\title{
Influence of the zirconia transformation on the thermal behavior of zircon-zirconia composites
}

\author{
Nicolas M. Rendtorff • Gustavo Suarez • \\ Yoshio Sakka $\cdot$ Esteban F. Aglietti
}

Received: 14 July 2011/Accepted: 1 September 2011/Published online: 23 September 2011

(C) Akadémiai Kiadó, Budapest, Hungary 2011

\begin{abstract}
During a heating-cooling cycle, zirconia $\left(\mathrm{ZrO}_{2}\right)$ undergoes a martensitic transformation from monoclinic to tetragonal structure phases, which presents special hysteresis loop in the dilatometry curve at temperatures between 800 and $1100{ }^{\circ} \mathrm{C}$. Monoclinic zirconia $\left(\mathrm{m}-\mathrm{ZrO}_{2}\right)$ particles reinforced ceramic matrix composites not always present this behavior. In order to elucidate this fact a series of zircon-zirconia $\left(\mathrm{ZrSiO}_{4}-\mathrm{ZrO}_{2}\right)$ ceramic composites have been obtained by slip casting and characterized. The final properties were also correlated with the zirconia content $(0-30 \mathrm{vol} . \%)$. The influence of the martensitic transformation $(\mathrm{m}-\mathrm{t})$ in well-dispersed zirconia grains ceramic composite on the thermal behavior was analyzed. Thermal behavior evaluation was carried out; the correlation between the thermal expansion coefficients
\end{abstract}

N. M. Rendtorff $(\bowtie) \cdot$ G. Suarez · E. F. Aglietti

Centro de Tecnología de Recursos Minerales y Cerámica (CETMIC): (CIC-CONICET-CCT La Plata), Camino Centenario y 506, C.C.49, M. B. Gonnet, B1897ZCA Buenos Aires, Argentina

e-mail: rendtorff@cetmic.unlp.edu.ar

N. M. Rendtorff · G. Suarez · E. F. Aglietti

Facultad de Ciencias Exactas, Universidad Nacional de La Plata,

47 y 115 La Plata, Buenos Aires, Argentina

N. M. Rendtorff

CIC-PBA, Buenos Aires, Argentina

G. Suarez · E. F. Aglietti

CONICET, La Plata, Buenos Aires, Argentina

Y. Sakka

Advanced Ceramic Group, Advanced Key Technologies

Division, National Institute for Materials Science (NIMS),

1-2-1, Sengen, Tsukuba 305-0047, Ibaraki, Japan with the zirconia content showed a deviation from the mixing rule applied. A hysteresis loop was observed in the reversible dilatometric curve of composites with enough zirconia grains $(\geq 10$ vol.\%). Over this threshold the zirconia content is correlated with the loop area. The transformation temperatures were evaluated and correlated with the zirconia addition. When detected the $\mathrm{m}-\mathrm{t}$ temperature transformation is slightly influenced by the zirconia content (due to the previously evaluated decrease in the material stiffness) and similar to the temperature reported in literature. The reverse (cooling) transformation temperature is strongly decreased by the ceramic matrix. The DTA results are consistent with the dilatometric analysis, but this technique showed more reliable results. Particularly the endothermic $\mathrm{m}-\mathrm{t}$ transformation temperature showed to be easily detected even when the only $\mathrm{m}-\mathrm{ZrO}_{2}$ present was the product of the slight thermal dissociation of the zircon during the processing of the pure zircon material.

Keywords Composites - Zirconia $\cdot$ Thermal behavior

\section{Introduction}

In many industrial applications, components are required to work in extremely hard conditions, particularly at very high temperatures for long times. For these applications, new ceramic matrix composites have been designed, with both micro- and nano-sized reinforcing particles, located at inter- or intra-granular positions, this can improve mechanical and thermomechanical performances as well as strongly reduce creep rate.

Many attempts are in progress to develop biphasic and tri-phasic [1-16] systems or even tetra-phasic systems [17-27]. Particularly much interest is still being carried 
out in dispersed zirconia containing ceramic composites with different contents of different types of $\mathrm{ZrO}_{2}$ grains [1-28].

Zirconia containing ceramics have attracted great attention to industrial applications in oxygen pumps, sensors, fuel cells, and thermal barrier coatings due to their excellent electrical, thermal, and mechanical properties [26]. Pure zirconia ceramic exhibits a phase transformation between monoclinic and tetragonal phases It can be seen that most of the reported $\mathrm{m}-\mathrm{t}$ and $\mathrm{t}-\mathrm{m}$ transformations temperatures are in the range of $1150-1120^{\circ} \mathrm{C}$ and $900-1100{ }^{\circ} \mathrm{C}$, respectively [27-34].

These transformations temperatures can be evaluated by different techniques like differential thermal analysis (DTA), differential scanning calorimetry, high-temperature $\mathrm{X}$-ray diffraction, neutron diffraction, dilatometry, and Raman scattering. As well as theoretical calculations based in first principles [29, 30].

Over the last decades, considerable advances have been made to improve the fracture toughness of ceramic systems. One of the most important examples is the toughening contribution from stress-induced martensitic transformation of tetragonal grains. Lathabai et al. [2] showed that significant toughening could be obtained by incorporating zirconia particles $\left(\mathrm{ZrO}_{2}\right)$ in a ceramic matrix. Different mechanisms are involved in the toughening of ceramic matrix originated by zirconia additions: stressinduced transformation, microcracking, crack bowing, and crack deflection. In all cases, the operative toughening mechanism depends on such variables as matrix stiffness, zirconia particle size, chemical composition, temperature, and strength.

There is a great technological interest to know the dilatometric behavior of a family of materials for hightemperature applications. It has been stated that the thermal expansion behavior of zirconia ceramics from a given powder type can be "tailored" within limits by changing the chemical composition and processing variables [35]. This provides some physical property selection capability for engineering applications.

One of the limiting behaviors of several zirconia containing materials is the thermal shock resistance. This behavior is strongly related to the thermal expansion behavior of the materials [35-38]. Different thermal conditions cause dimensional changes and consequently the magnitudes of the thermal stress are also dissimilar. Hence it is of technological importance to improve the understanding of this behavior particularly in the zirconia containing materials which present this special dilatometric behavior.

Zircon $\left(\mathrm{ZrSiO}_{4}\right)$ is a good refractory material because it does not undergo any structural transformation until its dissociation at about $1675{ }^{\circ} \mathrm{C}$. It exhibits many attractive properties for structural applications such as excellent chemical stability, a very low thermal expansion coefficient and low heat conductivity. These materials are specially used in such fields where severe chemical resistance together with sudden change of temperature may occur [36-40].

Particularly in zircon-based composites the thermal behavior of the triplex ceramic composite mullite-zirconia-zircon was studied recently [28], in the temperature range where materials exhibits thermal expansions and phase transformation $(m-t)$. The complexity of the effect of the zirconia content in the dilatometric behavior was established in both: the thermal expansion coefficient $\left(25-1000{ }^{\circ} \mathrm{C}\right)$ and hysteretic behavior of the complete reversible dilatometric curve.

There are several studies of ceramic-ceramic composite materials in which zircon acts as a continuous matrix in which different ceramic phases were introduced as particles, whiskers, or fibers [41-49].

Zircon materials have been also processed by several processing routes like: sol gel, aerosol, inverse micelle, reaction sintering, laser, etc. [36-38, 45, 46] particularly several reports have been published of zircon-based materials obtained by slip casting [37, 38], this processing route has several well-known advantages like low cost and the possibility of obtaining complex ceramic shapes that are impossible by other traditional or advanced ceramic processing routes, on the other hand is more difficult to obtain fully dense ceramic materials by this processing route.

The general objective is to understand the influence of the addition of dispersed zirconia grains to a continuous ceramic matrix. Particularly in the present work zircon $\left(\mathrm{ZrSiO}_{4}\right)$ was used as a ceramic matrix model. The densifications and the thermal behavior were also studied. Then a series of zircon-zirconia composites with equivalent dispersed zirconia particles imbibed in a zircon matrix by slip casting of concentrated aqueous dispersions were processed. Followed by the study of the influence of the zirconia content: in the sinterability, some mechanical properties and thermal behavior, particularly to study the effects of the zirconia martensitic transformation from $\mathrm{m}-\mathrm{t}$ and from $\mathrm{t}-\mathrm{m}$. The porosity, mean grain size, and distribution together with the microcracks developed by the martensitic transformation during processing (cooling) and the local thermal expansion mismatch between grains will also influence the dilatometric behavior of the composites.

The local thermal expansion mismatch between the constituent phases present in the composite is important. Furthermore, zirconia doubles zircon linear thermal expansion coefficient. The actual thermal expansion coefficients of these phases are shown in Table 1. 


\section{Experimental procedures}

A commercial zircon powder was used as principal raw material. Zircon was introduced on zirconium silicate (Mahlwerke Kreutz, Mikron, Germany), with $\mathrm{ZrO}_{2}=$ 64-65.5 wt $\%, \quad \mathrm{SiO}_{2}=33-34 \mathrm{wt} \%, \quad \mathrm{Fe}_{2} \mathrm{O}_{3} \leq 0.10 \mathrm{wt} \%$, and $\mathrm{TiO}_{2} \leq 0.15 \mathrm{wt} \%$, and $D_{50}=1.5 \mu \mathrm{m}$, and with a specific gravity of $4.6 \mathrm{~g} / \mathrm{cm}^{3}$. As a second starting powder monoclinic zirconia $\left(\mathrm{m}-\mathrm{ZrO}_{2}\right)$ with specific area of $14 \mathrm{~m}^{2} / \mathrm{g}$ and mean diameter $\left(D_{50}\right)$ of $0.2 \mu \mathrm{m}$ and $99.97 \%$ purity (TZ-0 Tosoh Co., Ltd. Japan). Composites were prepared from zircon and zirconia mixtures. The volumetric compositions and the labels employed are shown in Table 1.

Slip casting and sintering of zircon-zirconia composites

Slip cast compacts consisted of squared slabs. Concentrated $80 \mathrm{wt} \%$ suspensions at $\mathrm{pH} 9.1-9.2$ were prepared by adding the powder to aqueous solutions with $0.5 \%$ of dispersant (Dolapix CE64, Zschimmers and Schwartz) and $\mathrm{NH}_{4} \mathrm{OH}$ [37, 38]. After mixing, the suspensions were ultrasonicated for $20 \mathrm{~min}$ and de-aired in a vacuum chamber (less than 10 Torr) for more than 10 min during a continuous stirring. The slip casting was performed in porous alumina molds, and left to dry in the air for $48 \mathrm{~h}$. Samples of different prismatic shapes were cut in $4 \times 3 \times 15 \mathrm{~mm}^{3}$ samples from the green compacts obtained for the subsequent characterizations. Probes were sintered at a heating rate of $10{ }^{\circ} \mathrm{C} / \mathrm{min}$ up to $1600{ }^{\circ} \mathrm{C}$ for $2 \mathrm{~h}$ and then cooled to room temperature at $10{ }^{\circ} \mathrm{C} / \mathrm{min}$. In order to evaluate the sinterability, other samples were also fired at 1300,1400 , and $1500{ }^{\circ} \mathrm{C}$. A dilatometry analysis of the green compacts was performed from room temperature up to $1350{ }^{\circ} \mathrm{C}$. This test was carried out with a high-temperature dilatometer (TMA system: TMA8310, Rigaku Japan.) $10{ }^{\circ} \mathrm{C} / \mathrm{min}$ as heating and cooling rates.

\section{Materials characterization}

Density and apparent porosity of the sintered samples (1300-1600 ${ }^{\circ} \mathrm{C}$ ) was evaluated by the Archimedes method.

The crystalline phases of the sintered samples were determined by X-ray diffraction (XRD) using $\mathrm{Cu} \mathrm{K} \alpha$ radiation operating at $40 \mathrm{kV}$ and $30 \mathrm{~mA}$. The materials microstructure characterization was done with a Scanning Electron Microscope (SEM) (Hitachi, Miniscope TM 3000, Japan). The surfaces of the specimens were polished with diamond slurries of $15,9,6,3,1$, and $0.25 \mu \mathrm{m}$ diameter.

Vickers Hardness (Hv) was evaluated with a Vickers indentation machine (Akashi AVK-A, Japan) at least eight indents using a $5 \mathrm{~kg}$ load for $15 \mathrm{~s}$. Later the dynamic elastic modulus $\left(E_{\mathrm{Exp}}\right)$ of the composites was measured by the excitation technique with a GrindoSonic (Belgium),
MK5 "Industrial" Model on samples with the following dimensions: $4 \times 3 \times 30 \mathrm{~mm}^{3}$. A theoretical estimation of the elastic modulus $\left(E_{\text {theo }}\right)$ was calculated with the following expression:

$E_{\text {theo }}=\sum_{i} E_{i} \times V_{i}$

where $E_{i}$ and $V_{i}$ are the elastic modulus and the volume fraction of each crystalline phase (Table 1)

Thermal behavior evaluation

The thermal expansion behavior of sintered ceramics from 25 to $1250{ }^{\circ} \mathrm{C}$ (heating) and from 1250 to $400{ }^{\circ} \mathrm{C}$ (cooling) was evaluated. The tests were carried with the same dilatometer using air atmosphere. The final dimension of the sample was $4 \times 3 \times 15 \mathrm{~mm}^{3}$. Data for precise calculation of thermal expansion coefficient were measured in the temperature range $25-1000{ }^{\circ} \mathrm{C}$ at a heating rate of $10{ }^{\circ} \mathrm{C} /$ min during heating. Alumina was used as standard for the dilatometric experiments.

Experimental thermal expansion coefficients $\left(\alpha_{\text {Exp }}\right)$ were also compared to a theoretical thermal expansion coefficient $\left(\alpha_{\text {theo }}\right)$ estimated from the following equation:

$\alpha_{\text {theo }}=\sum_{i} \alpha_{i} \times V_{i}$

where $\alpha_{i}$ and $V_{i}$ are the corresponding thermal expansion coefficients and volume fraction of each phase of the composite material, shown in Table 1.

The differential thermal analyses together with the thermo gravimetric (TG) analysis were carried out simultaneously for the sintered samples in NETZSCH 409/c equipment. They were carried out using a $10^{\circ} \mathrm{C} / \mathrm{min}$ heating rate up to $1400{ }^{\circ} \mathrm{C}$ and were cooled at the same rate down to $400{ }^{\circ} \mathrm{C}$. Samples of approximately $600 \mathrm{mg}$ were analyzed in a platinum crucible and dynamic air atmosphere, using pure alumina as reference material.

Table 1 Phases properties and composition of the composites

\begin{tabular}{|c|c|c|c|}
\hline & & Zircon & Zirconia \\
\hline \multicolumn{2}{|c|}{ Chemical composition } & $\mathrm{ZrSiO}_{4}$ & $\mathrm{ZrO}_{2}$ \\
\hline \multicolumn{2}{|c|}{ Thermal expansion coefficient $/ 10^{-6}{ }^{\circ} \mathrm{C}$} & 4.5 & 10.0 \\
\hline \multicolumn{2}{|c|}{ Elastic modulus $(E) / \mathrm{GPa}$} & 240 & 200 \\
\hline Sample & \multicolumn{2}{|c|}{ Content/vol.\% } & \\
\hline ZSZ0 & \multicolumn{2}{|l|}{100} & 0 \\
\hline ZSZ10 & \multicolumn{2}{|l|}{90} & 10 \\
\hline ZSZ20 & \multicolumn{2}{|l|}{80} & 20 \\
\hline ZSZ30 & \multicolumn{2}{|l|}{70} & 30 \\
\hline
\end{tabular}




\section{Results and discussions}

The materials processing and properties

The green density of the dried compacts was measured after slip casting; values are shown in Table 2 together with the theoretical ones. The green density increases with the zirconia content of the composites, and is in all the cases around $70 \%$ of the theoretical density of the two starting powders mixture. After the $1600{ }^{\circ} \mathrm{C}$ thermal treatment the density of the composites increased up to $90 \%$ of the theoretical one while the density of the pure zircon material was over the $93 \%$. This fact shows that sinterization decrease by the addition of the zirconia to the initial formula. The porosity is below $5 \%$ for the whole group of composites. These values of density and porosity are comparable to the ones achieved for similar materials by the same processing route $[25,27-40,46,50]$.

Figure 1 shows the final density and porosity of the different composites obtained at different sintering temperatures between 1300 and $1600{ }^{\circ} \mathrm{C}$. As expected, density grows and porosity decreases with the sintering temperature. The pure zircon material sintered in an easier way than the composite materials.

Figure 2 shows a part (from $1000{ }^{\circ} \mathrm{C}$ ) of the dilatometric curve of the green compacts. Although in Table 2 and Fig. 1 it was evident that the ZSZ0 materials sintered more easily, it is clear that this material is the one that starts sintering later than the other ones. In fact the ZSZ30 composite starts to contract below $1100{ }^{\circ} \mathrm{C}$, and the ZSZ0 does it almost one hundred degrees later. Once it starts to sinter the densification is faster. Perhaps the shrinkage observed in the three composite materials (at the beginning) corresponds to the nano zirconia grains coalescence that occurs at a lower temperature and later, the densification of the zircon matrix takes place. This is why over $1350{ }^{\circ} \mathrm{C}$ the pure zircon material is the one that present the highest shrinkage. This two stage sintering processes may be responsible of the increase of the porosity with the $\mathrm{ZrO}_{2}$ content.

Figure 3 shows the XRD patterns of the obtained materials at $1600{ }^{\circ} \mathrm{C}$, the principal crystalline phase

Table 2 Green, sintered, and theoretical densities of the materials studied

\begin{tabular}{llll}
\hline Sample & $\begin{array}{l}\text { Green density/ } \\
\mathrm{g} \mathrm{cm}^{-3}\end{array}$ & $\begin{array}{l}\text { Sintered density/ } \\
\mathrm{g} \mathrm{cm}^{-3}\end{array}$ & $\begin{array}{l}\text { Theoretical density/ } \\
\mathrm{g} \mathrm{cm}^{-3}\end{array}$ \\
\hline ZSZ0 & 3.16 & 4.27 & 4.56 \\
ZSZ10 & 3.21 & 4.14 & 4.67 \\
ZSZ20 & 3.32 & 4.28 & 4.78 \\
ZSZ30 & 3.45 & 4.50 & 4.89 \\
\hline
\end{tabular}

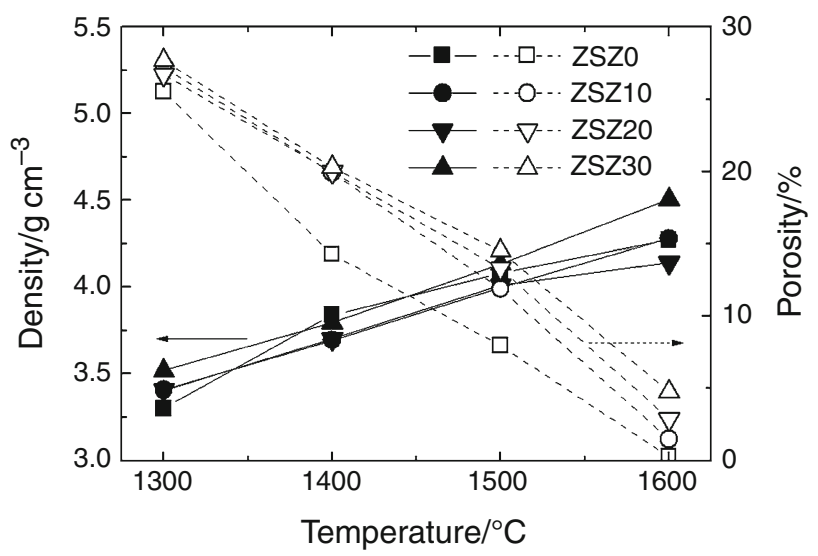

Fig. 1 Sintered density and porosity of the sintered materials at different temperatures

detected are zircon $(\mathrm{Z})$ and monoclinic zirconia $(\mathrm{m})$. The detail in the top left corner of Fig. 3 shows the expected gradual increase in $\mathrm{m}-\mathrm{ZrO}_{2}$ in the series of zircon-zirconia composites. Furthermore small zirconia diffraction is detected for the pure zircon material evidencing a partial (small) thermal dissociation of zircon into zirconia and silica. This was also reported before for similar materials $[49,51,52]$. Although the actual dissociation temperature of zircon is $1675{ }^{\circ} \mathrm{C}$ the presence of impurities decreases this temperature importantly [51]. It can be conclude that no important crystalline phase changes occur during the processing at $1600{ }^{\circ} \mathrm{C}$. Is also important to point out that tetragonal zirconia is not detected in the sintered compacts.

Figure 4a-d shows the typical SEM images of the composite materials. All the samples had a dense microstructure with low residual pore presence which is similar to that reported in previous works [37, 39, 49, 51, 52] taking into account the processing route (slip casting). Always two types of grains were observed: the uniformly dispersed grains of zirconia (white) and the zircon matrix (gray), finally the glassy bonding phase can be detected (dark gray). While the atomic ratio $\mathrm{Si}: \mathrm{Zr}$ was close to the unity in the zircon grains it was nearly four when the local EDAX analysis was carried out to this darker zone.

The grain size was below $4 \mu \mathrm{m}$ for the zircon, while the zirconia grains remained below $2 \mu \mathrm{m}$ in all the materials. Also it is important to point out that in the first composite (ZSZ10) zirconia grains are isolated in the zircon matrix while in the ZSZ20 some of them are grouped in two, and in the ZSZ30 composite these groups are even bigger but the percolation limit was not achieved. It is also important to point out that the grains presented a rounded morphology for both the matrix and the dispersed zirconia phase. In conclusion for the purpose of the next analysis it can be assumed that these materials are equivalent in terms of microstructure configuration, and that the only variable was 


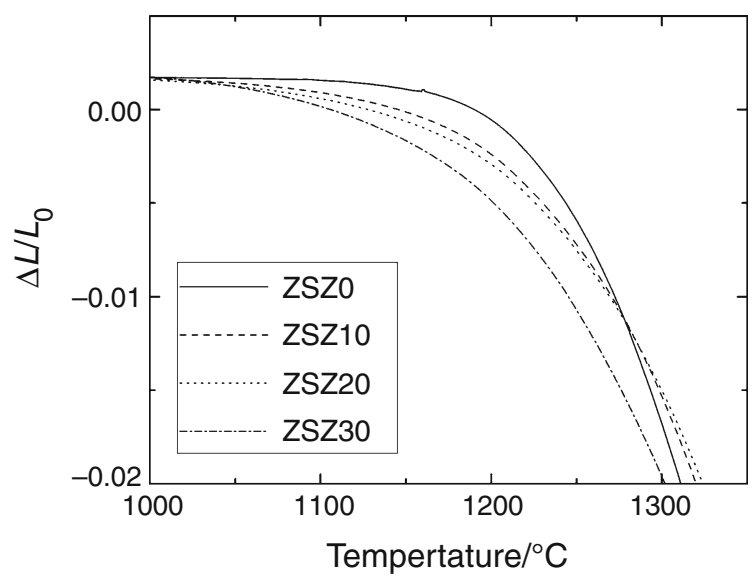

Fig. 2 Densification of the zircon-zirconia composites at $10{ }^{\circ} \mathrm{C} / \mathrm{min}$

the amount of monoclinic zirconia grains imbibed in the zircon ceramic matrix.

\section{Mechanical properties}

The theoretical and experimental elastic modulus $\left(E_{\text {Theo }}\right.$ and $E_{\mathrm{Exp}}$ ) of the obtained materials are shown in Table 3. Taking into account the actual values for each phase (Table 1) a gradual decrease in the dynamic modulus was expected with the $\mathrm{m}-\mathrm{ZrO}_{2}$ content increase. But the values observed were even lower than expected. Firstly the microstructure of the materials presents some inherent defects like residual porosity, grain boundaries, etc. (Fig. 4a-d); but this is similar in the four materials studied. The greater reduction can be explained by two facts: the

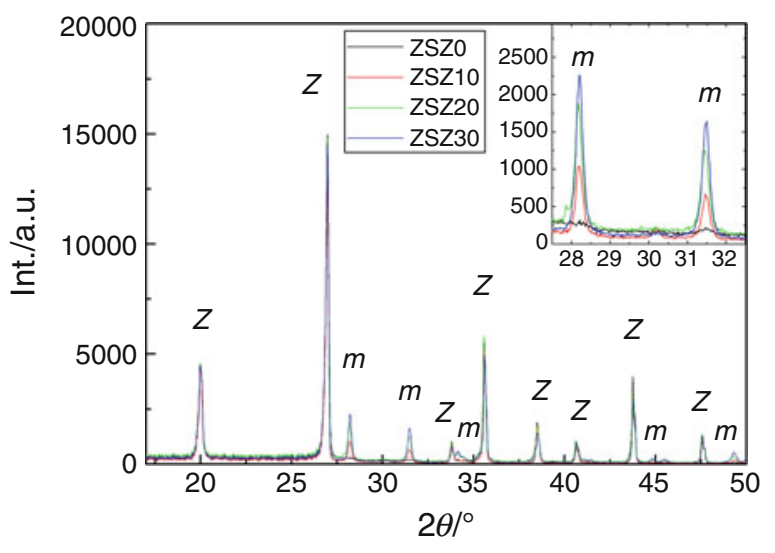

Fig. 3 XRD patterns of the zircon-zirconia materials $\left(\mathrm{Z} \mathrm{ZrSiO}_{4}\right.$ and $m \mathrm{~m}-\mathrm{ZrO}_{2}$ )

local thermal expansion mismatch between the two phases and by the consequences of the presence of the zirconia grains that during the processing thermals cycle suffer a phase transformation from monoclinic to tetragonal and vice versa that is accompanied by a volume change responsible of the appearance of microcracks $[25,27,28$, 30, 32-34]. These two mechanisms that deteriorate the microstructural integrity developing some extra defects introduce an important decrease in the elastic constants [27]. These defects could also be the cause of the increase in the porosity evaluated by the Archimedes method.

In Table 3, also shows the Vickers hardness values as a function of the zirconia content, showing a parallel decrease of $\mathrm{Hv}$, showing that the mechanical properties of the material are also diminished. Both mechanisms depend
Fig. 4 SEM image of the studied materials: a ZSZ0, b ZSZ10, c ZSZ20, d ZSZ30
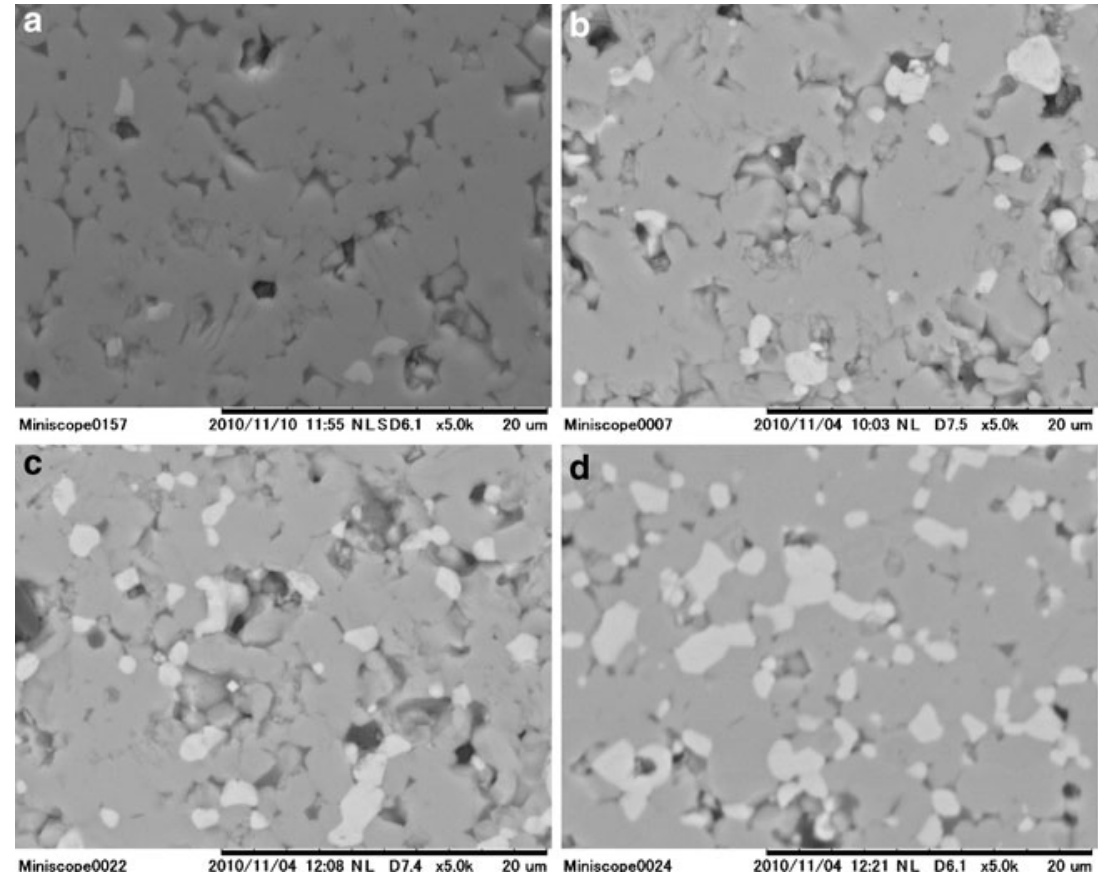
Table 3 Hardness, experimental dynamic elastic modulus, and theoretical elastic modulus of the materials studied

\begin{tabular}{llll}
\hline Sample & $\mathrm{Hv} / \mathrm{kg} \mathrm{mm}^{-2}$ & $E_{\text {Exp }} / \mathrm{GPa}$ & $E_{\text {Theo }} / \mathrm{GPa}$ \\
\hline ZSZ0 & 810 & 210 & 240 \\
ZSZ10 & 610 & 160 & 236 \\
ZSZ20 & 540 & 144 & 232 \\
ZSZ30 & 600 & 136 & 228 \\
\hline
\end{tabular}

on the thermal behavior of these composite materials that is evaluated in the following section.

Thermal behavior

\section{Thermal expansion coefficient $\left(\alpha_{\text {exp }}\right)$}

Figure 5 shows the heating dilatometric curve of the studied composites from room temperature to $1000{ }^{\circ} \mathrm{C}$. The gradual increase with the addition of the $\mathrm{m}-\mathrm{ZrO}_{2}$ from the initial formula is evident.

The linear fit of the dilatometric curves of the composites was satisfactory (in this temperature range) hence the experimental linear thermal expansion coefficient $\alpha_{\exp }$ (25-1000 ${ }^{\circ} \mathrm{C}$ ) was evaluated from the slope of the linear fitting result of each material. In all cases, the fitting parameters $R$ were over 0.98 . The values of $\alpha_{\exp }$ as a function of the additive content is shown in Table 4 together with the theoretical value estimated from Eq. 2. It is easy to find Eq. 3 after expanding and rearranging Eq. 2.

$\alpha_{\text {Theo }}=\alpha_{\mathrm{ZrSiO}_{4}}+\left(\alpha_{\mathrm{ZrO}_{2}}-\alpha_{\mathrm{ZrSiO}_{4}}\right) \times V_{\mathrm{ZrO}_{2}}$

$\alpha_{\text {Theo }}=4.5+(5.5) \times V_{\mathrm{ZrO}_{2}}$

Using the literature values of the two phases (Table 1) it can be found that the theoretical slope for the mixing rule for this binary composite is equal to $5.5 \times 10^{-6}{ }^{\circ} \mathrm{C}^{-1}$.

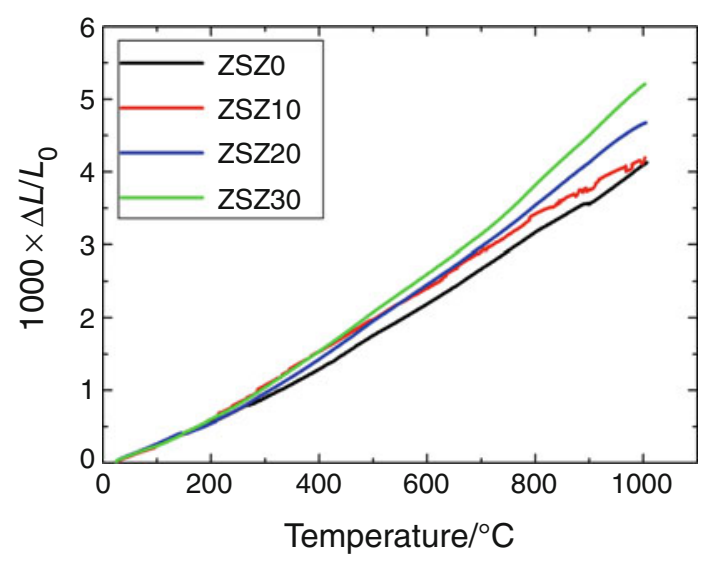

Fig. 5 Dilatometric curves of the zircon-zirconia composites $\left(25-1000{ }^{\circ} \mathrm{C}\right)$
The linear fitting results of the experimental coefficients $\left(\alpha_{\text {exp }}\right)$ as a function of the zirconia content is showed in the following equation:

$\alpha_{\text {Exp }}=4.15+(3.65) \times V_{\mathrm{ZrO}_{2}}$

Although the correspondence between the theoretical model and the experimental data was not quantitative the tendency is evident in a qualitative way and a kind of mixing rule could be defined, that will be suitable for interpolation. The difference between the experimental evaluation and the theoretical estimation of the thermal expansion coefficient might be explained by the presence of porosity, the grain size, and distribution together with the microcracks developed due to the martensitic transformation, the same reason can explain de differences observed in the $E$ elastic modulus correlation and the decrease of hardness $(\mathrm{Hv})$ (Table 3). The local thermal expansion mismatch between grains also influences the dilatometric behavior of the composites. All these factors reduced the thermal expansion of the composite and were detected in these composites previously by scanning electron microscopy and mechanical and fracture characterization [25, 28].

The lower value of the experimental slope (Eq. 5) compared to the theoretical slope (Eq. 4) also demonstrates the effect of the zirconia contents is not only consequence of its higher thermal expansion coefficient. These were also supported by the fact that the deviation of the pure zircon material is lower than the composite materials as seen in Table 4. This behavior was also observed in the triplex mullite-zirconia-zircon composites [28] but the constants (Eq. 5) differed from the ones obtained in the present study showing that this is qualitative similar but that the effect of the zirconia depends on the ceramic matrix and particle size together with the other variables.

\section{Dilatometric hysteresis}

The $\mathrm{m}-\mathrm{t}$ transformation in $\mathrm{ZrO}_{2}$ is believed to be martensitic it was previously well described [27-29]; however, the details such as the transition path from the monoclinic to the tetragonal phase is properly not known [29]. The transformation induce by some changes (benefits) on the

Table 4 Experimental and theoretical thermal expansion coefficients $\left(25-1000{ }^{\circ} \mathrm{C}\right)\left(\alpha_{\text {exp }}\right)$ of the zircon-zirconia composites as a function of the $\mathrm{m}-\mathrm{ZrO}_{2}$ content (vol.\%)

\begin{tabular}{llll}
\hline Sample & $\mathrm{m}-\mathrm{ZrO}_{2} / \mathrm{vol} . \%$ & $\alpha_{\mathrm{Exp}} / 10^{-6}{ }^{\circ} \mathrm{C}^{-1}$ & $\alpha_{\text {Theo }} / 10^{-6}{ }^{\circ} \mathrm{C}^{-1}$ \\
\hline ZSZ0 & 0 & 4.21 & 4.50 \\
ZSZ10 & 10 & 4.44 & 5.05 \\
ZSZ20 & 20 & 4.85 & 5.60 \\
ZSZ30 & 30 & 5.29 & 6.15 \\
\hline
\end{tabular}


mechanical behaviors of zirconia containing materials through several mechanisms of toughening (microcracks toughening, transformation toughening, etc. [26, 27]. It is accompanied by a volume change of approximately 5 vol.\%. It consists in shrinkage in the heating cycle and enlargement in the cooling cycle. Besides, the transformation occurs in a range of temperatures depending on the matrix stiffness where the zirconia particle is embedded [27-29, 33, 34]. The particle size also influences this transformation. Particles smaller than a critical size do not go through the reverse transformation and remain in a meta-stable tetragonal form at room temperature. Wang et al. [31] did a complete review on these transformation temperatures $(\mathrm{m}-\mathrm{t}$ and $\mathrm{t}-\mathrm{m})$.

This volume changes can be observed in the dilatometric evaluation of the composites and presents the typical hysteresis form [28]. This particular expansion behavior could be negative for the composite application. Excessive $\mathrm{ZrO}_{2}$ content surely affects the thermal shock resistance and strength $[24,25]$.

In Fig. 6 the complete reversible (up to $1250{ }^{\circ} \mathrm{C}$ ) dilatometric curves of the studied composites are shown. In order to achieve a better visualization, the curves were vertically translated. The hysteresis loop is clearly present for ZSZ30 and ZSZ20 composites and it is not observed for the material ZSZ10 and the pure Zircon material (ZSZ0). The enlargement of the ZSZ30 samples evaluated by this method was important, and is another indirect evaluation of the microcracks introduced to the microstructure by the zirconia incorporation.

\section{True alpha (differential dilatometry)}

The dilatometric curve (full line) and its respective differential, assumed to be the true expansion coefficients $\left(\alpha_{\text {true }}\right)$ at different temperatures are shown in Fig. 7a and b for ZSZ30 and ZSZ20 samples. The general behavior of the $\alpha_{\text {true }}$ is similar: Firstly the curve was nearly constant up to $1150{ }^{\circ} \mathrm{C}$; then an important negative peak is observed (set off $=1153{ }^{\circ} \mathrm{C}$ ), coinciding with the $\mathrm{m}-\mathrm{t}$ shrinkage. In the cooling cycle a second negative peak is observed around $900{ }^{\circ} \mathrm{C}$ (set off $=917^{\circ} \mathrm{C}$ ) that corresponds to the $\mathrm{t}-\mathrm{m}$ transformation of the $\mathrm{m}-\mathrm{ZrO}_{2}$. Both transformation temperatures decreased with zirconia content decrease; the $\mathrm{m}-\mathrm{t}$ set off of the negative peak of the ZSZ20 sample, showed in Fig. $7 \mathrm{~b}$, was at $1017^{\circ} \mathrm{C}$ and for the $\mathrm{t}-\mathrm{m}$ transformation was at $762{ }^{\circ} \mathrm{C}$. This was also observed in the triplex composites studied in a previous work [28]. Furthermore, the transformations were not detected by dilatometry for materials with 10 vol.\% of $\mathrm{ZrO}_{2}$ (Fig. 6) and the pure zircon material. In ZSZ30 the heating $\mathrm{m}-\mathrm{t}$ peak is sharper than the cooling $\mathrm{t}-\mathrm{m}$ peak; this difference is even grater for ZSZ20. Moreover, as mentioned the reverse $\mathrm{t}-\mathrm{m}$

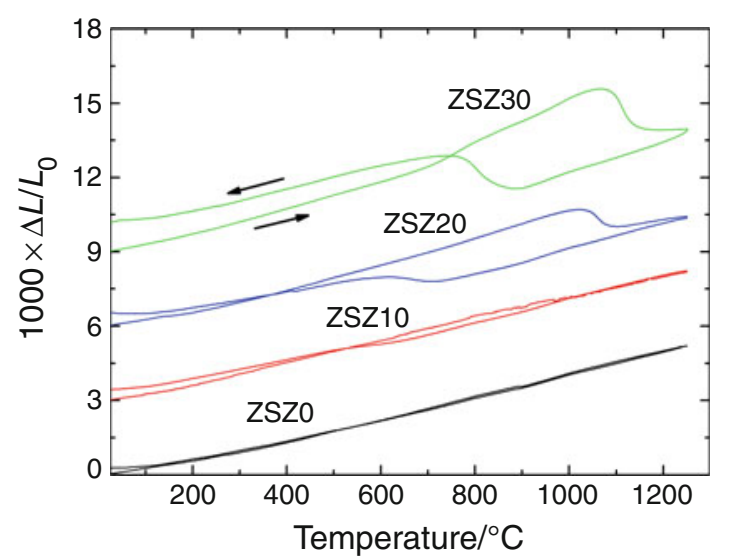

Fig. 6 Complete reversible dilatometric curves of the zircon-zirconia composites $\left(25-1250-25{ }^{\circ} \mathrm{C}\right)$
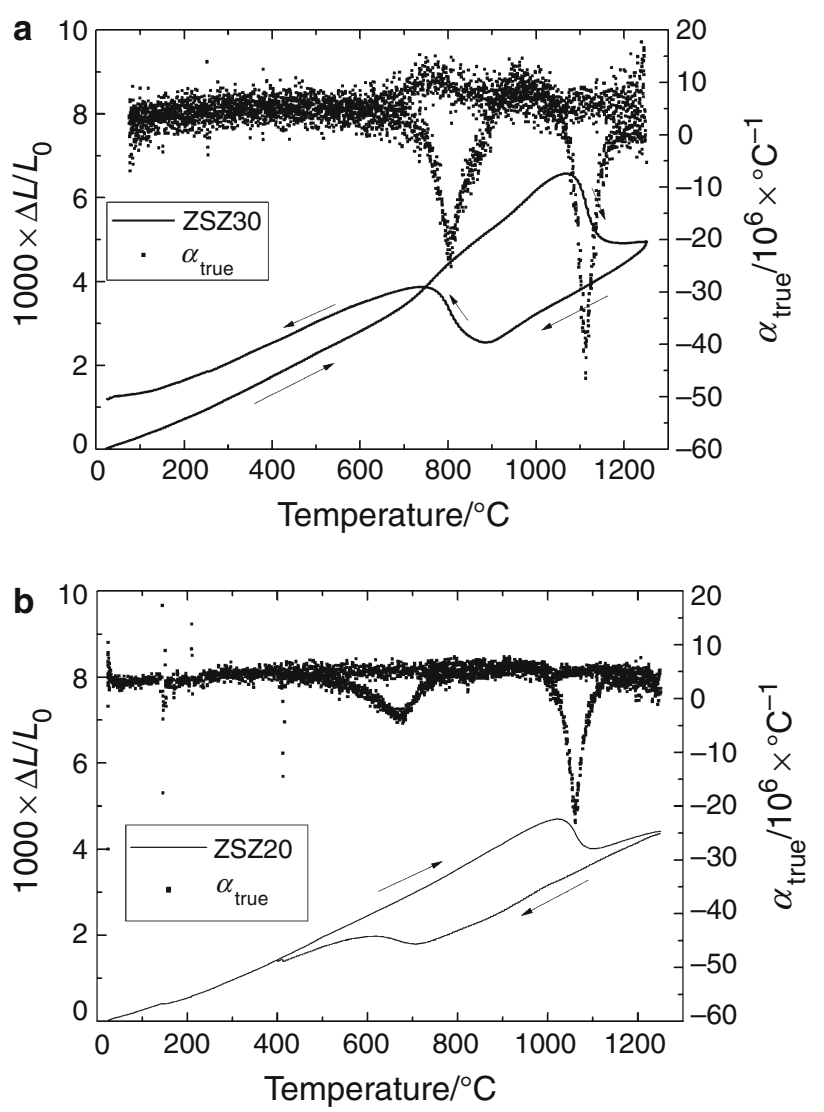

Fig. 7 Dilatometric and differential dilatometric curves of the ZSZ30 (a) and ZSZ20 (b) composites

transformation was retarded, in other words occurred at lower temperature.

The hysteresis loop area was related with the $\mathrm{m}-\mathrm{ZrO}_{2}$ content. This was evaluated by the differences in the graphical integration of the heating and cooling curves (between 500 and $1250{ }^{\circ} \mathrm{C}$ ). The values of the hysteresis loop area for the different composites as a function of the 
$\mathrm{m}-\mathrm{ZrO}_{2}$ content are shown in Fig. 8. Clearly for composite with less than 10 vol.\% of $\mathrm{m}-\mathrm{ZrO}_{2}$ the loop was undetected; hence the microstructure absorbs the volume changes of the dispersed particles. The loop area of composites containing over this threshold value of $\mathrm{m}-\mathrm{ZrO}_{2}$ increased with the zirconia content. Therefore, the loop area can be used for the estimation of the amount of $\mathrm{m}-\mathrm{ZrO}_{2}$ present in related composites.

\section{$D T A-T G$}

As was mentioned, the transformation temperatures on heating and cooling are affected by many factors such as particle size, impurities, stress, and thermal history of materials. The literature data reports large discrepancies, and no quantitative analysis has been carried out yet on how these factors can affect the transformation temperatures [27-34].

The differential thermal analyses together with the TG analysis were carried out simultaneously on the sintered samples. They were completed with a $10^{\circ} \mathrm{C} / \mathrm{min}$ heating rate up to $1400{ }^{\circ} \mathrm{C}$ and were cooled at the same rate down to $400{ }^{\circ} \mathrm{C}$.

The reversible martensitic transformation of zirconia can be detected by DTA [28, 29]. The DTA diagrams showed an endothermic peak, corresponding to the $\mathrm{m}-\mathrm{t}$ transformation at $\approx 1150{ }^{\circ} \mathrm{C}$ during the heating cycle. Also an exothermic peak at $\approx 1000{ }^{\circ} \mathrm{C}$ throughout the cooling cycle appears so; the transformation temperatures can be evaluated. As expected, weight changes from the TG analysis were not significant.

Monoclinic to tetragonal transformation temperature detected by DTA corresponds satisfactorily with the one detected by dilatometric analysis. But the reverse transformation detected by DTA presents some differences with the thermodynamic transformation temperature, showing

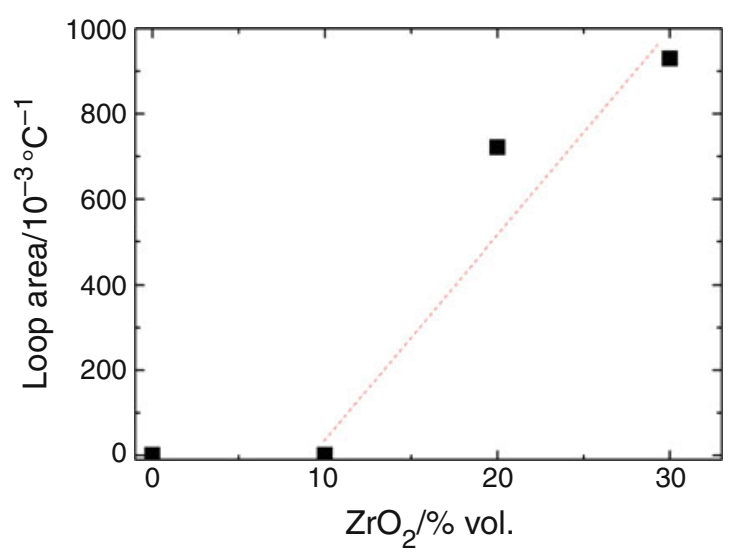

Fig. 8 Martensitic hysteresis loop area of the dilatometric curves of the zirconia-zircon composites the effect of the ceramic matrix in which it is imbibed. The temperature at which occurs the transformation decreases with the zirconia content. This result is comparable to the ones obtained by dilatometry ("Dilatometric hysteresis" and "True alpha (differential dilatometry)" sections). This could be explained by the decrease in the elastic modulus observed (Table 3 ).

The DTA for the four materials are shown in Fig. 9; heating and cooling cycles were separated to achieve a better examination. Both vertical scales are the same; hence the peaks intensities are comparable.

As established by XRD analysis (Fig. 4) and SEM (Fig. 4a-d) the four materials present certain amount of zirconia. In $\mathrm{ZSZ0}$, the $\mathrm{ZrO}_{2}$ comes from the dissociation during sintering while in the others ZSZ10-30 the zirconia was introduced in the starting formula. This transformation is expected to be detected by DTA although the transformation enthalpy is no very high (transformation enthalpy around 5000-6000 J/mol [28]).

The four materials presented the $\mathrm{m}-\mathrm{t}$ endothermic peak at around $1130{ }^{\circ} \mathrm{C}$ on the heating cycle that corresponds to the $\mathrm{m}-\mathrm{t}$ transformation that was also observed by dilatometric evaluation. The actual temperature is also shown in Fig. 9. The intensity, calculated as the peak area, is plotted as a function of the zirconia content in Fig. 10. This is clearly proportional to the zirconia content. Furthermore, the temperature decreased with the zirconia content because the material stiffness also decreased (Table 3) due to the incorporation of the zirconia. In other words, the addition of zirconia to the matrix influenced its own transformation temperature.

On the other hand, higher concentration materials (ZSZ20 and ZSZ30) presented the $\mathrm{t}-\mathrm{m}$ exothermic peak during the cooling cycle but in the other two materials with low $\mathrm{m}-\mathrm{ZrO}_{2}$ content (less $10 \mathrm{vol} . \%$ ) the peak was not
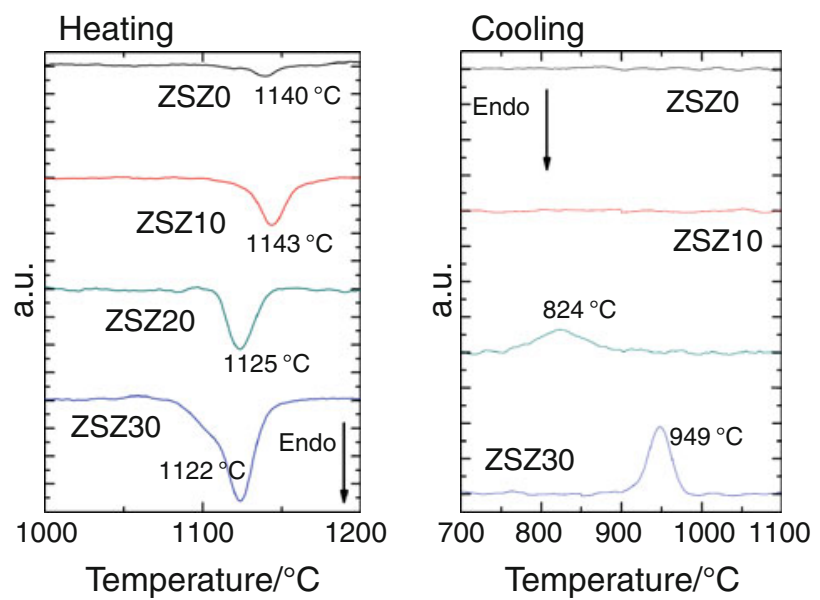

Fig. 9 Differential thermal analysis (DTA) of the zircon-zirconia composites 


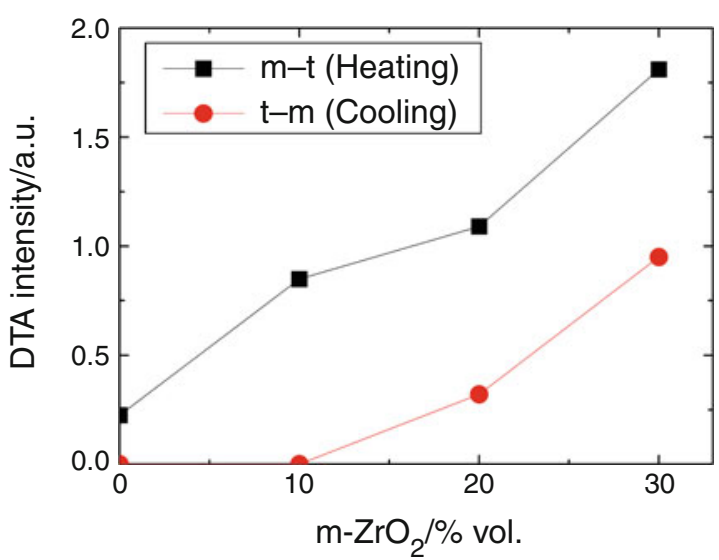

Fig. 10 DTA phase transformation peaks intensity as a function of the zirconia content

detected by DTA. The transformation for these diluted materials was not detected by dilatometric analysis either (Figs. 6, 7, 8). But as no important amount of $\mathrm{t}-\mathrm{ZrO}_{2}$ was detected in the XRD patterns of the composites the transformation might occurred but not detected by this technique perhaps it takes place in excessively wide temperature range.

Again the intensity of the $t-m$ transformation DTA peak is plotted as a function of the zirconia content in Fig. 10. The results are equivalent to the ones obtained for the dilatometric loop area plotted in Fig. 8. Furthermore, the temperature at which this peak appears (for ZSZ20 and ZSZ30) do not corresponds to the one reported in literature [27] and was importantly influenced by the zirconia content (diminished in the diluted composite), the actual temperatures are shown in the corresponding plot in Fig. 9. Also the peak width was higher in the ZSZ20 material than in the ZSZ30 material, perhaps in the ZSZ0 and ZSZ10 materials is too width that it becomes undetectable. This decrease in the temperature was also identified by dilatometry (Fig. 7). Showing that in the diluted materials the stiffness of the matrix retarded the reverse transformation.

\section{Conclusions}

Thermal analysis techniques, especially dilatometric and DTA study showed to be a useful technique for studying zirconia containing composites. The influence of zirconia content was established. The phase transformation effects were correlated with the dilatometric behavior of zirconia containing zircon composites.

The mechanical properties evaluated were comparable to the ones reported for similar materials. A gradual increase in the thermal linear expansion coefficient with the increase of the zirconia content of the composites was observed below $1000{ }^{\circ} \mathrm{C}$. This effect was lower than a theoretical prediction with a mixing rule, indicating that the effect of $\mathrm{ZrO}_{2}$ is more complex. Moreover, as mentioned, an indirect evaluation of the microcracks developed during processing was evidenced like in the dynamic elastic modulus evaluation. The dynamic elastic modulus (E) showed a similar deviation to the direct mixing rule, which could be also consequence of microcracks development due to the m-zirconia transformation and local thermal expansion mismatch with the zircon matrix.

The influence of the martensitic transformation $(m-t)$ in well-dispersed zirconia grains ceramic composite on the thermal behavior was analyzed. A hysteresis loop was observed in the reversible dilatometric curve of composites with enough zirconia grains $(\geq 10$ vol.\%). Over this threshold the zirconia content is correlated with the loop area. The transformation temperatures were evaluated and correlated with the zirconia content. During the heating cycle, the $m-t$ temperature is slightly influenced by the zirconia content (due to the previously evaluated decrease in the materiel stiffness) and similar to the temperature reported in literature. The reverse transformation is strongly decreased by the ceramic matrix and the temperature at which occurs decreases with the increase in the zirconia content. Also the temperature range is broadened. However, no tetragonal zirconia was detected in the materials at room temperature.

Finally the DTA results are consistent with the dilatometric analysis, but this technique showed more reliable results. Particularly the endothermic $\mathrm{m}-\mathrm{t}$ transformation showed to be easily detected even when the only $\mathrm{m}-\mathrm{ZrO}_{2}$ present was the product of the slight thermal dissociation of the zircon during the processing of the pure zircon material.

\section{References}

1. Torrecillas R, Moya JS, De Aza S, Gros H, Fantozzi G. Microstructure and mechanical properties of mullite-zirconia reactionsintered composites. Acta Metall Mater. 1993;41(6):1647-52.

2. Lathabai S, Hay DG, Wagner F, Claussen N. Reaction-bonded mullite/zirconia composites. J Am Ceram Soc. 1996;79(1): 248-56.

3. Hamidouche M, Bouaouadja N, Osmani H, Torrecillias R, Fantozzi G. Thermomechanical behavior of mullite-zirconia composite. J Eur Ceram Soc. 1996;16(4):441-5.

4. Jang B-K. Microstructure of nano $\mathrm{SiC}$ dispersed $\mathrm{Al}_{2} \mathrm{O}_{3}-\mathrm{ZrO}_{2}$ composites. Mater Chem Phys. 2005;93(2-3):337-41.

5. Hirvonen A, Nowak R, Yamamoto Y, Sekino T, Niihara K. Fabrication, structure, mechanical and thermal properties of zirconiabased ceramic nanocomposites. J Eur Ceram Soc. 2006;26(8): 1497-505.

6. Sarkar D, Adak S, Mitra NK. Preparation and characterization of an $\mathrm{Al}_{2} \mathrm{O}_{3}-\mathrm{ZrO}_{2}$ nanocomposite, Part I: Powder synthesis and transformation behavior during fracture. Compos Part A. 2007;38(1):124-31. 
7. Yugeswaran S, Selvarajan V, Dhanasekaran P, Lusvarghi L. Transferred arc plasma processing of mullite-zirconia composite from natural bauxite and zircon sand. Vacuum. 2008;83(2):353-9.

8. Rendtorff N, Garrido L, Aglietti E. Thermal shock behavior of dense Mullite-Zirconia composites obtained by two processing routes. Ceram Int. 2008;34(8):2017-24.

9. Belhouchet H, Hamidouche M, Bouaouadja N, Garnier V, Fantozzi G. Elaboration and characterization of mullite-zirconia composites from gibbsite, boehmite and zircon. Ceramics-Silikaty. 2009;53(3):205-10.

10. Ibarra Castro MN, Almanza Robles JM, Cortés Hernández DA, Escobedo Bocardo JC, Torres Torres J. Development of mullite/ zirconia composites from a mixture of aluminum dross and zircon. Ceram Int. 2009;35(2):921-4.

11. Mecif A, Soro J, Harabi A, Bonnet JP. Preparation of mullite- and zircon-based ceramics using kaolinite and zirconium oxide: a sintering study. J Am Ceram Soc. 2010;93(5):1306-12.

12. Chockalingam S, Traver HK. Microwave sintering of $\beta$-SiAlON$\mathrm{ZrO}_{2}$ composites. Mater Des. 2010;31(8):3641-6.

13. Tür YK, Sünbül AE, Yilmaz H, Duran C. Effect of mullite grains orientation on toughness of mullite/zirconia composites. Ceram Trans. 2010;210:273-8.

14. Curran DJ, Fleming TJ, Towler MR, Hampshire S. Mechanical properties of hydroxyapatite-zirconia compacts sintered by two different sintering methods. J Mater Sci: Mater Med. 2010;21(4): 1109-20.

15. Ma W, Wen L, Guan R, Sun $X$, Li X. Sintering densification, microstructure and transformation behavior of $\mathrm{Al}_{2} \mathrm{O}_{3} / \mathrm{ZrO}_{2}\left(\mathrm{Y}_{2} \mathrm{O}_{3}\right)$ composites. Mater Sci Eng A. 2008;477(1-2):100-106.

16. Sahnoune F, Saheb N, Chegaar M, Goeuriot P. Microstructure and sintering behavior of mullite-zirconia composites. Mater Sci Forum. 2010;638-642:979-84.

17. Calderon-Moreno JM, Yoshimura $\mathrm{M}$. $\mathrm{Al}_{2} \mathrm{O}_{3}-\mathrm{Y}_{3} \mathrm{AlO}_{12}(\mathrm{YAG})-$ $\mathrm{ZrO}_{2}$ ternary composite rapidly solidified from the eutectic melt. J Eur Ceram Soc. 2005;25(8):1365-8.

18. Hamidouche M, Bouaouadja N, Torrecillas R, Fantozzi G. Thermomechanical behavior of a zircon-mullite composite. Ceram Int. 2007;33(4):655-62.

19. Naglieri V, Palmero P, Montanaro L. Preparation and characterization of alumina-doped powders for the design of multiphasic nano-microcomposites. J Therm Anal Calorim. 2009;97 (1):231-7.

20. Shevchenko AV, Dudnik EV, Ruban AK, Redko VP, Lopato LM. Sintering of self-reinforced ceramics in the $\mathrm{ZrO}_{2}-\mathrm{Y}_{2} \mathrm{O}_{3}-\mathrm{CeO}_{2}-$ $\mathrm{Al}_{2} \mathrm{O}_{3}$ system. Powder Metall Metal Ceram. 2010;49(1-2):42-9.

21. Malek O, Vleugels J, Perez Y, De Baets P, Liu J, Van den Berghe $\mathrm{S}$, Lauwers B. Electrical discharge machining of $\mathrm{ZrO}_{2}$ toughened WC composites. Mater Chem Phys. 2010;123(1):114-20.

22. Sarkar SK, Lee BT. Evaluation and comparison of the microstructure and mechanical properties of fibrous $\mathrm{Al}_{2} \mathrm{O}_{3}-\left(\mathrm{m}-\mathrm{ZrO}_{2}\right) / \mathrm{t}-$ $\mathrm{ZrO}_{2}$ composites after multiple extrusion steps. Ceram Int. 2010;36(6):1971-6.

23. Pan C, Zhang L, Zhao Z, Qu Z, Yang Q, Huang X. Changes in microstructures and properties of $\mathrm{Al}_{2} \mathrm{O}_{3} / \mathrm{ZrO}_{2}\left(\mathrm{Y}_{2} \mathrm{O}_{3}\right)$ with different content of $\mathrm{ZrO}_{2}$. Adv Mater Res. 2010;105-106(1):1-4.

24. Rendtorff N, Garrido L, Aglietti E. Mullite-zirconia-zircon composites: properties and thermal shock resistance. Ceram Int. 2009;35(2):779-86.

25. Rendtorff N, Garrido L, Aglietti E. Zirconia toughening of mullite-zirconia-zircon composites obtained by direct sintering. Ceram Int. 2010;36(2):781-8.

26. Zender $\mathrm{H}$, Leistner $\mathrm{H}$, Searle $\mathrm{H}$. $\mathrm{ZrO}_{2}$ materials for applications in the ceramic industry. Interceram. 1990;39(6):33-6.

27. Kelly P, Rose LF. The martensitic transformation in ceramics-its role in transformation toughening. Prog Mater Sci. 2002;47: 463-557.
28. Rendtorff NM, Garrido LB, Aglietti EF. Thermal behavior of mullite-zirconia-zircon composites. Influence of zirconia phase transformation. J Therm Anal Calorim. doi:10.1007/s10973010-1030-3.

29. Wang C, Zinkevich M, Aldinger F. The zirconia-Hafnia system: DTA measurements and thermodynamic calculations. J Am Ceram Soc. 2006;89(12):3751-8.

30. Luo X, Zhou W, Ushakov SV, Navrotsky A, Demkov AA. Monoclinic to tetragonal transformations in hafnia and zirconia: a combined calorimetric and density functional study. Phys Rev B. 2009;80(13):134119.

31. Wang $\mathrm{C}$, Zinkevich $\mathrm{M}$, Aldinger $\mathrm{F}$. On the thermodynamic modeling of the Zr-O system. Calphad. 2004;28(3):281-92.

32. Chevalier J, Gremillard L, Virkar AV, Clarke DR. The tetragonal-monoclinic transformation in zirconia: lessons learned and future trends. J Am Ceram Soc. 2009;92(9):1901-20.

33. Moriya Y, Navrotsky A. High-temperature calorimetry of zirconia: heat capacity and thermodynamics of the monoclinic-tetragonal phase transition. J Chem Thermodyn. 2006;38(3):211-23.

34. Skovgaard M, Ahniyaz A, Sørensen BF, Almdal K, van Lelieveld A. Effect of microscale shear stresses on the martensitic phase transformation of nanocrystalline tetragonal zirconia powders. J Eur Ceram Soc. 2010;30:2749-55.

35. Ownby PD, Burt DD, Stewart DV. Experimental study of the thermal expansion of yttria stabilized zirconia ceramics. Thermochim Acta. 1991;190(1):39-42.

36. Mori T, Yamamura H, Kobayashi H, Mitamura T. Preparation of high-purity $\mathrm{ZrSiO}_{4}$ using sol-gel processing and mechanical properties of the sintered body. J Am Ceram Soc. 1990;75(9): 2420-6.

37. Moreno R, Moya JS, Requena J. Slip casting of zircon by using an organic surfactant. Ceram Int. 1991;17(1):37.

38. Garrido LB, Aglietti EF. Zircon based ceramics by colloidal processing. Ceram Int. 2001;27(5):491-7.

39. Shi Y, Huang X, Yan D. Fabrication of hot-pressed zircon ceramics: mechanical properties and microstructure. Ceram Int 1997;23(5):457-62.

40. Carbonneau X, Hamidouche M, Olagnon C, Fantozzi G, Torrecillas R. High temperature behavior of a zircon ceramic. Key Eng Mater. 1997;132-136:571-4.

41. Shi Y, Huang X, Yan D. Mechanical properties and toughening behavior of particulate-reinforced zircon matrix composites. J Mater Sci Lett. 1999;18(3):213-6.

42. Singh RN. High-temperature mechanical properties of a uniaxially reinforced zircon-silicon carbide composite. J Am Ceram Soc. 1990;73(8):2399-406.

43. Singh RN. Mechanical properties of a zircon matrix composite reinforced with silicon carbide whiskers and filaments. J Mater Sci. 1991;26(7):1839-46.

44. Singh RN. SiC fibre-reinforced zircon composites. Am Ceram Soc Bull 1991;70(I):55-56.

45. Shi Y, Huang X, Yan D. Toughening of hot-pressed $\mathrm{ZrSiO}_{4}$ ceramics by addition of Y-TZP. Mater Lett. 1998;35(3-4):161-5.

46. Alahakoon WPCM, Burrows SE, Howes AP, Karunaratne BSB, Smith ME, Dobedoe R. Fully densified zircon co-doped with iron and aluminium prepared by sol-gel processing. J Eur Ceram Soc. 2010;30(12):2515-23.

47. Kondoh I, Tanaka T, Tamari N. Sintering of zircon-silicon carbide whisker composites and their mechanical properties. J Jpn Ceram Soc. 1993;101(3):369-72.

48. Shi Y, Huang X, Yan D. Synergistic strengthening and toughening of zircon ceramics by the additions of $\mathrm{SiC}$ whisker and $3 \mathrm{Y}$ TZP simultaneously. J Eur Ceram Soc. 1997;17:1003-10.

49. Rendtorff NM, Garrido LB, Aglietti EF. Mechanical and fracture properties of zircon-mullite composites obtained by direct sintering. Ceram Int. 2009;35(7):2907-13. 
50. Tartaj P, Sanz J, Serna CJ, Ocana M. Zircon formation from amorphous spherical $\mathrm{ZrSiO}_{4}$ particles obtained by hydrolysis of aerosols. J Mater Sci. 1994;29(24):6533-8.

51. Kaiser A, Lobert M, Telle R. Thermal stability of zircon $\left(\mathrm{ZrSiO}_{4}\right)$. J Eur Ceram Soc. 2008;28(11):2199-211.
52. Váczi T, Nasdala L, Wirth R, Mehofer M, Libowitzky E, Häger T. On the breakdown of zircon upon "dry" thermal annealing. Miner Petrol. 2009;97:1-129. 